http://dx.doi.org/10.4314/ejotmas.v7i1-2.27

\title{
AESTHETICISM IN VISUAL SYMBOLS: CATALYSTS FOR THEATRE PATRONAGE IN CONTEMPORARY PLAY PRODUCTION
}

*Bernard Eze ORJI

\begin{abstract}
Theatre practice in Nigeria like the world over is in a state of constant flux due to the ever emerging new trends. New concepts, styles, forms are continuously on demand as a result of the insatiable human tastes in performance and coupled with a civilization in which technological advancement and human creativity are not left out in its wake. The emergence of the social media has come to add more pressure on the live theatre from where the film medium stopped. Nigerian theatre patrons and sponsors have little or nothing to do again at the theatre at least, not with mobile phones such as i-phones, i-pads, tabs, blackberry and android, serving as forms of entertainment on the go. Therefore, wooing and keeping the live theatre audience will take extra energy and this can only be achieved if the visual appeal trend is revolutionized with a quantum deployment of visual aesthetics. The beauty of play production is ensconced in visual symbolism since theatre communication makes use of two of the human senses principally the visual and the aural. These senses are in the main, complementary and supportive, its functions are numerous to the point that a theatre performance will be close to being meaningless without their application - be it in its superfluity, moderateness or aesthetically immoderate. This article, therefore, articulates those visual symbols required by a director and his or her production team to capture and sustain his or her audience in a theatre. Having employed a qualitative research approach, the paper established that visual symbols such as lighting, scenery, costume, sound, and makeup are ready tools at the disposal of the director in achieving the visual aesthetics of a theatre production so as to keep his or her audience and continuously enjoy their patronage.
\end{abstract}

Keywords: Aesthetics, Visual Symbols, Contemporary Theatre Production, Theatre Director

*Bernard Eze ORJI is of the Department of Theatre Arts, Alex Ekwueme Federal University, Ndufu-Alike Ikwo, Nigeria

Email: bernard.orii@funai.edu.ng 


\section{Introduction}

The beauty of theatre production is embedded in visual symbolism. This is creating images in their picturesqueness to enhance communicative propensities of a play. Play production is a dynamic and flexible endeavour which involves the amalgam of various professionals in a collaborative effort to make a unified and a gestalt art form that will expose the wrangling of man in the society, pursuant to derivation of satisfaction in entertainment, relaxation and recreation which are inescapable human quests. Play production as a collaborative art, has its planning, control, coordination, evaluation, assessment and overseership in the able hand of one individual called the director. Facts emanating from experiences show that no two directors given the same cast and crew, same resources as well as venue can possibly come out with the same result. There are bound to be distinctions in every play production. This difference emanates from individual director's perception, conception, imaginative and creative outputs. This applies with visual symbolism as well. Visual symbolism as a director's tool is imbedded in his imaginative creativity and his coordinative propensity to bring the play into physical and aesthetic wholesomeness. These are made possible through forms, textures, symbols, lines, circles, balance and picturization to create meaningful communication in the theatre experience.

It is against this background that this paper believes that, in an age where technology has transformed every aspect of life, including performance, the deployment of visual symbols in play production becomes an interesting aspect of the whole theatre experience. Therefore, any theatrical activity or dramatic enactment without the synthesis of these audio-visual elements is more or less a pseudotheatre. This position resonates in the words of Ododo thus, "adequate use of (design and) technical aids can better the lots of theatre performance. In the case of modern Nigerian theatre practice, the playwright, director and the actors have necessary involvement if the visual essence of their arts is to be enhanced" (109). Visual symbolism has been on the steady rise in Nigeria theatre production. Even though its role is in the main, supportive and complementary, its functions are numerous to the point that a play production will be close to being meaningless without their application. The reason being that visual symbolism creates a living environment for the actors in the theatre and helps to translate visions, ideas, and the total theatre experience into a picturesque form, thereby highlighting the communicative propensity of theatre productions.

Every theatre production is either meant to be seen and or heard. In the words of Enendu: Theatre production depends almost entirely 
on sound and visual components for meaningful entertainment and communication; each one, to an extent, complementing the other. The audience comes into the theatre to see and hear the performance (The Sight...17).

Yet instances abound where production is devoid of the trappings of visual symbols and reduced to the barest minimum of visual accompaniments. For example, Peter Brooks believes that a theatre experience has taken place when an actor crosses the stage and is watched by an audience. The house lights dim, and we see a solitary actor standing in the centre of a bare stage. There is almost nothing to support the actor - simple work lights, no costume, no set, nothing but blankly lit empty space. Downs, Wright and Ramsey ask; could this be theatre? Absolutely! (195). However, our creative and intelligent Nigerian audience will not spare his coin over such shabby and shoddy performance, hence the need for visual symbols to support and create a befitting living environment for the actors, a place where even sponsors and patrons would be happy to identify with and even put their money. The trio of Downs, Wright and Ramsey believe that:

\begin{abstract}
When sets, lights, sounds, and costumes are added, the audience is immersed in the world of the play even before the first line is spoken. Theatre is intended to be experienced by our eyes, our ears, our mind, our whole being, so theatre has always had designers in one form or another to help create the experience (195).
\end{abstract}

\title{
Nigeria Theatre Director and Production Peculiarities
}

The success of any theatre production depends largely on how well the director analyses and synthesizes the script into a physical and practical composition. Play directing is an onerous task with its challenges and peculiarities. It involves the director's articulation and deployment of ingenuity, composition, movement, and picturization using the actors and the stage décor. In play production, one of the director's many tasks is putting the play on stage in such a way as to create meaningful impacts and suggestive imageries to the audience and actors alike. The director must as a matter of fact and necessity know the types of stage and the production peculiarities and potentialities the stage holds before choosing the type of performance style appropriate for the production and significantly the required composition of the visual symbols. There are different types of performance space available for the director to choose from. These include the arena, the thrust, the proscenium and the found (informal) 
spaces, all having their strong and weak points. But one thing the director does principally is creating a visual opportunity for the splendid exchange of communicativeness and the flow of meaning between actors and actors, actors and the audience. The director, according to Kernodle " $\ldots$ is visualizing an action involving people with people and people with the world they live in" (368). He employs five techniques to achieve this. Kernodle lists them to include, "composition, picturization, movement, pantomimic dramatization and rhythm. The first two - composition and picturization are techniques for controlling the picture in space and the last three set the play into movement in time." The significance of this Kernodle observes, "is to make the play clear and meaningful to the eye, as though the spectators were deaf, and to the ear, as though they were blind" (367). He further reiterates that, "the composition of the picture and picturization of relationships must be planned and controlled completely by someone outside the picture" (368), that person is the director, who in his wisdom employs the distancing approach to peep and ensure that the stage figures are properly placed to avoid muddled up picturization. Taking a cue from Kernodle, Sean McBride enthuses that, "visual communication is a basic form of expression which this century has seen dramatically, visualized by the invention of moving images carried by the cinema or television screen (4).

The director's job goes beyond merely guiding the actors in terms of blockings. Bassey Effiong defines directing as "...the uses to which the flora and fauna of an author's script or idea are revealed artistically and scientifically on stage before an audience" (iv). He further states that the person on whose shoulders this recreation process lies is the "regisseur" or "metteur en scene" or more appropriately the professional director. Bassey also reveals that the decades between 1944 and 1994 actually marked the exploration, experimentation as well as the evolution of the Nigerian theatre director.

The idea of the Nigerian theatre director is believed to have cropped up in 1960. Wole Soyinka, it is recorded, wrote and directed A Dance of the Forest, for Nigeria's independence celebration. This was the very first time in Nigeria that a play production provided "... some medium of realism such as flats and levels instead of symbolically painted borders on baft were introduced" (iv). The major boost to Nigerian theatre directing was, the "return from abroad of Ola Rotimi as well as Dapo Adelugba in the mid-sixties ushered in the era of wellmade theatre director" ( $v$.). Talking about the return of the Rotimis and Adelugbas, Bassey Effiong observes that "between 1965-1977 these geniuses not only exhibited what theatre directing is all about but also the pains of teaching the techniques of play directing" (v.). $\mathrm{He}$ further articulates that directing involves "the harmonization of the 
disparate but symbolic organs of production process, thus affecting the fusion of the unseen (crew or stage hands) and the seen (on stage acts) performance in a symbolic exploration towards self artistic and audience satisfaction.

The emphasis of this paper rests squarely on the satisfaction of the audience which is termed 'theatre patrons' in this paper. Satisfying the audience in a theatre production is not only the bidding of actors, but the coming together of all the units that make up the production process. According to Edwin Wilson, "the audience forms an indispensable element in the theatre equation because theatre occurs only when spectators are present to interact with performers and identify with the character being portrayed" (8). Most importantly is the role of the visual symbol in arresting and sustaining the interest of the theatre goers (theatre patrons). To be able to sustain these interests, audience members according to Edwin Wilson, "bring more than their mere presence; they bring a background of personal knowledge and a set of expectations that shape the experience" (44). Lobel Adrianne (a set designer) believes that "a good design needs to connect with the piece (production) in a way that keeps surprising, and keeps allowing the audience to have ideas and revelations as the evening goes on" (Downs, Wright and Ramsey, 205).

Theatrical growth is achievable by an overt acceptance of the communicativeness of the methods, techniques, moods and skills used by the actors as ascertained by the director for an audience during the theatrical process. Grotowski defines this as "what takes place between the actor and the spectator (audience) (33). It is the total effect realized in the duality of purpose in the performance and response in the theatre experience. It is what creates the sustenance, acceptableness, continuation and evolution of the theatre. This emerges from the rhythm, composition, picturization, movement and the pantomimic interpretations which constitute part of the visual aspects of the theatre experience.

\section{Visual Symbols in Theatre Production}

Design is an act of transformation. In working with a director, a designer transforms words into a world within which actors are engaged in human action. It might be a metaphoric world, an emotional world or an architectural world, but it is a process of bringing design ideas into a place where they can be executed. Ming Cho Lee, Theatre Designer (in Downs, Wright and Ramsey 196).

Theatre is essentially communication between two groups of people - the performer and the audience. The average theatre practitioner is used to art as one of his greatest tools for externalizing 
his thoughts, emotions, desires, skills and experiences. Even though he uses gestures, body movements and other visual aspects of communication, these are mainly the supplement and not equivalent to speech. Yet, these same non-verbal or visual symbols are the onus of the magic of the theatre. But do these visual symbols just occur or do they come out from the blues? They must be planned, procured and executed effectively, as tools to enhance the theatrical communication. This is the business of assemblage in a theatre space and the aptness of the opening quote above. Space in the theatre like every other space is a void, full of emptiness, thus meaningless. It can only become useful for the theatre experience once defined, demarcated and made functional. This designation is achievable through the use of flats, lights, borders, drops, backdrops, drapes, scenery, set props, and symbols as to enhance the central metaphor of the production; to beef up characterization, mood, and atmosphere as the demands of the production require. These symbols either implied or suggestive help to garnish the play with an abstract but creative approach.

In the arts of the theatre, visual symbols are the mainstay of expressiveness in communication. They shape a play into a complete communication encounter. This is achievable through the creative impetus of the theatre director in collaboration with his team of designers, craftsmen and artisans. In discussing the visual tools, emphasis will be given to proscenium staging. As one of the most versatile and challenging forms of staging due to its undirectionality in viewership, through the proscenium opening, it creates ample chances for mood, visibility, composition and plausibility, as aspects of realism to be achieved. George Kernodle believes that theatre is a "visual art...each theatre craftsman must develop his skill yet subordinate it to the plan, the idea, the particular style, of the production." (336). The concept of theatre as a unified art is, according to Kernodle, distinctly modern. In his words:

A hundred years ago people went to the theatre to see a play "put on" or performed by glamorous actors, with costumes and scenery added as decorative afterthought. But the art of the theatre was redefined in the revolutionary decades from 1895 to 1915 by Adolphe Appia and Gordon Craig, who showed how line, colour, and shape of setting, costume, and lighting must be an integral part of the play, as important as words. Craig in particular saw the need for a 
single creative mind; that of a director trained in all the separate crafts of the theatre, to make a central plan for the production and to see that this idea was carried out in the movement, line, colour, and rhythm of the performance. (336)

Visual symbolism in theatre is a product of design or theatre technology. Theatre technology is exemplified in stage lighting, scene design, properties, theatre architecture, sound and acoustics, and costume and makeup. For the sake of this paper, sound is treated infinitesimally for the mere fact that it primarily creates mood and atmosphere for the better understanding of the visual symbols. Emphasis will be placed on stage lighting, scene design, properties and costume and makeup. However, technology is not the only factor of enhancing visualization. Movement, Rhythm, Composition, Picturization and Pantomimic representation are all aspects of visualization deployed as visual symbols in modern play production.

\section{a. The Play's Living Environment (Scene Design)}

A stage in its architectural structure is likened to a void and can only become meaningful if demarcated to suit the demands of a particular production. This is the living environment of the actors. This is the scene design in action. It is the setting of the play, the requirements notwithstanding. Over the years, the environment of the play had been anything and depending on the theatrical styles adopted by the director and designers alike. From bare stage (Peter Brook), poor theatre (Gerzy Growtosky), simplified or suggested realism, realism, symbolism, expressionism, to computer aided designs (CAD), which has become the rave of the modern times. Despite these attempts at creating different theatrical styles in scene design by designers and directors, the functionality of the set design and other visual symbols have not changed and according to George Kernodle, "the design creates an environment for the actor - a pedestal, a showcase, a picture, a machine for acting. It gives the actor form, contrast, and mood as it shapes the play in both space and time" (409). Kernodle took us memory lane to assert that, "in the nineteenth century, the main function of scenery was to indicate time and place. The painted backdrops, along with the costumes, told the audience they were in Spain or China, ancient, medieval, or modern times, prince's palace or peasant's kitchen" (409). The chronicle of the trajectories in the history of set design was captured succinctly by the trio of Downs, Wright and Ramsey in these words: Twenty-five hundred years ago in ancient Greece, designers painted screens, sewed costumes, and 
built masks to help create the characters and suggest the play's virtual environment. During the Italian Renaissance, designers constructed elaborate stage settings using two-dimensional flats that were painstakingly painted to appear as if they were three-dimensional throne rooms, landscapes, and dungeons. At other times in theatre's history, the set design has been simple. For example, for hundreds of years Chinese opera was performed outdoors on bare platforms. Instead of complex designs, settings were indicated with simple symbolic gestures of the actors or with minimal set pieces (204).

Scene design therefore serves the purpose of providing the locale for which the production is set, provides a functional acting base and sets the pace, rhythm, unity, composition and picturalization of the theatre production. The scene designer, together with the lighting designer, the costumier and in collaboration with the director set the visual style and demands of the production. Because of their training and experience in the arts of the theatre, these people have almost unlimited possibilities of modifications to suit the needs of a particular production. In the same vein, Roderick Ham AADIPL Riba notes that the stage setting in modern theatre: Assists visual expression of the dramatic performance by providing a geography for the actor within the stage space, assisting the action and contributing to the atmosphere of the play and clarifying the time and place of the action. It also serves to screen other visual distractions from the audience (92).

Variety, they say is the spice of life. The eyes, like most of the sensory organs, rely on variety for continuous and exciting moments in its existence. Monotony calls for boredom, dullness and stagnation. The theatre, more than any other human endeavour is built on variety - variety in styles of theatre production, theatre architecture, writing styles, acting styles, design styles, and even styles in the deployment of visual symbols.

\section{Stage Lighting}

Light is the most important medium on stage... without its unifying power, our eyes would be able to perceive what objects were but not what they expressed... what can give us this sublime unity which is capable of uplifting us:...light! Adolphe Appia (qtd in Downs, Wright and Ramsey, 210).

However, to corroborate the aura, grandeur and splendor of stage light in modern times, this assertion by George Kernodle testifies to its truism: The audience is held spellbound as the house lights go down, the curtains disappear, and the lights bring form out of nothingness. Both the actor and the setting emerge in bold relief, 
creating highlights and shadows in the controlled plastic light of the spotlights. Then, as the action moves from one part of the stage to another, the light gets stronger there and the rest of the stage recedes into the margin of attention. For light, even more than the setting, shapes the action and exerts a hypnotic control over the interest and emotions of the audience (442).

Every stage production is meant to be seen. Be it in the arena, the thrust, the proscenium or informal or found spaces, light is an integral part of any stage performance. Even in the earliest of times, going back to the Greek period, the Athenians gathered at the foot of Acropolis mountain at the theatre of Epidaurus as early as sighting the first rays of the morning sun to watch their tragedians in a drama contest during the festival in honour of Dionysus, their god of wine, fertility and creativity. Just like in our traditional African festivals, setting and light have never been an issue. For according to Orji:

\begin{abstract}
African theatre uses no scenery and depends upon sunlight for natural lighting and visibility. It employs a minimal number of props, and the scenes in the performance are set in ordinary places known to the audience already; in front of homes, in a village square, along the village bush tracks and prominently in the market arena. The visual effects therefore, depend upon the contrasts achieved through the physical movement, colours, and the juxtaposition of differently costumed masked players. (71)
\end{abstract}

This position is aptly captured in Downs, Wright and Ramsey when they enthused that, "for thousands of years theatre was performed outdoors, so the sun provided the light. Many of these preelectricity civilizations built their theatres so that the afternoon sunshine would hit the stage" (205). In theatrical lighting, the age of electricity can boast of its superiority to all other ages. It has perfected an art that started when primitive actors thousands of years ago danced with flaming torches... while the Greeks and the Elizabethans used the open sky and most medieval performances took place in the daytime... (Kernodle 443). Even though light in its imaginative deployment can create mood and intensity in the theatre, or stage, it is not just done in void. Its planning and execution varies from production to production depending on the demands of that particular stage production, the architectural limitations of lighting positions in the theatre and the design propensities of the light designer as to his understanding of the general and detail concepts of the play. It is 
against this backdrop that Enendu's declaration becomes sacrosanct. According to him, "the lighting design should be based on details and particular consideration of the technical means by which the design effects are to be achieved. Basics are the energy source, the number of circuits and the dimmers, the types and the characteristics of lanterns both ordinary instrumentation and for special effects" (Fundamental Reflections...136). However, apart from illuminating the actor, and the setting, light as a means of artistic expression is an important aspect of drama. This is achievable by creating a controllable direction; intensity, colour and mood to create variation and contrast and also convey the atmosphere through an already planned architecture housing the lights. Enendu reveals inter alia:

The architecture of theatre is planned with provisions and considerations for technical and artistic requirements of light. Quite recently, the measure of the successes and functionality of a theatre building is based, among other things on the theatre's ability to conveniently and comfortably provide for the hanging and operations of the multilantern stage system and integrating them to the conception of the production. (The Effects of Architectural...172-173)

The epicenter of all light depositories in theatre is the control room. Like all control rooms such as in University of Ibadan Soyinka Arts Theatre, University of Calabar Chinua Achebe Arts Theatre, University of Lagos Main Auditorium, National Theatre Complex Iganmu, Lagos, Agip Hall, Lagos, Muson Centre Lagos to mention but a few, the control room serves as the engine house and the livewire of all light and sound effects of any theatrical productions. It is where the electric switch panels, fire alarm control panel, inter-communication switch system, stage-lighting and stage sound control systems are located. The theatre as has already been described is "an experience in sight and sound." This goes to ascertain the truism that the control room is the hub of the theatre productions. Frederick Bentham offers a rather generous clarification on the co-relation of the art of stage lighting and theatre building. He asserts that: We cannot have a theatre without light, for a theatre is by definition a place of viewing. If this holds for the director, it holds for the designer, and still more for the architect. Light is the most intractable medium he has to handle in creating his building... theatre planning, architecture and scene design, electrical technology, physics in the shape of optics and colour, 
manufacturing processes and economics, all are of vital concern to stage lighting (11).

The most important necessity in theatre planning to the technical director i.e. the lighting designer, his technicians, master electrician, the focusing and running crew is the accessibility of lighting instruments wherever they are found in the theatre. Thus, the traffic system from the control room through the projection room to the cat-walk and from the cat-walk cum loading galleries must have interconnectivity. All the lanterns from the various lighting positions are linked at the dimmer rack and to the lighting console through a network of electrical wiring using a $2.5 \mathrm{~mm}$ cable. The console in the control room is used to vary the intensity of light during a play or theatrical production. With the varying intensity, colours, and the availability of workable lighting position, and the appropriate gadgets, coupled with the creative and imaginative impetus of the lighting designer, lights can create a splendor of magic. This is when used in its aesthetic functionalities.

\section{Designing the Costumes and Makeup}

Costumes and makeup are Siamese twins in every theatrical production. These two come handy as major complements to enhance the overall production. They can be exaggerated or reduced to its barest accompaniments depending on the demands of the production (including budget) and the ingenuity of the director and designers. Costumes and makeup as visual symbols in the theatre are carefully planned and integrated with the actor and the action so as to create spectacular images in the eyes of the audience. Utoh-Ezeajugh defines costume as, "the items of clothing, accessories and ornamentation worn by the actor or actress for the purpose of defining character and establishing the circumstances of the character's existence, by situating him/her in time and space." In continuation, she defines makeup "as instruments, materials and substances used to design the face, head and other exposed parts of the body of an actor or actress" (130). As far back as man can remember, costume and makeup have been an integral part of any theatrical production. The early man through mimesis and in a bid to hunt for game and survive in the forest costumed and made up to resemble the animals in the wide. Downs, Wright and Ramsey capture the art of costuming in theatre historically thus:

As long as there has been theatre, there have been costumes. In precolonial African theatre, masks and costumes were an integral part of the performance. Four hundred years before the birth of Christ, the 


\begin{abstract}
Greeks used costumes in their tragedies to reveal the character's mood and enhance their performances. In Shakespeare's day, wealthy lords and ladies donated their worn gowns and leggings to the local theatre so that actors might have a variety of outfits to choose from. Costumes can be exaggerated like those in the Japanese Kabuki theatre or understated, as is often the case in modern realistic plays. (214).
\end{abstract}

In play production, a play that is costumed shows careful selection of the clothes to project the characters to the audience. Clothes tell the audience the age, occupation and social status of the wearer. A well-selected costume should tell the audience many things about the character even before he speaks. In play productions, makeup is integrally related to costuming as lighting is to scene design. Buchman quoted in Utoh-Ezeajugh asserts that: The vital link between the artist and the audience is stage makeup. This final tool, when properly used, allows the performer to utilize his face to protect his role to the audience. Without this skill, all other aspects of his training are badly undermined (132).

And for costume which cannot be separated from makeup in its dramatic values, Rusell captures it in these glowing terms: Costumes are the moving scenery of a production, and when worn by the actors, who are the centre of all dramatic action, they are the strongest element of the visual scene; they project personality and individual emotion and obtain the strongest audience focus (Utoh-Ezeajugh, 132).

The success of any theatrical production to a large extent depends on the deployment of these design elements of costume and makeup. Costume and makeup are therefore essential in theatre production since plays, dances arts, musical arts, can fully be appreciated in conjunction with these elements of visual symbol worn physically by the actors before a live audience in the theatre for proper role interpretation and production embellishments.

\title{
Sound and Music
}

Sound and Music are an integral part of every theatre production. Whether defined, incorporated or adopted to serve in any aspect, they contribute to establish and clarify the concept or the production philosophy. In fact, the usefulness of sound and music in theatre production can never be underestimated. It is a known fact that sounds and music in the theatre are an age long phenomena. Francis Hodge quoted by Edde lji asserts that, "a play production is an experience in 
sound as well as in sight" (9). lji reveals further that sound and music are used in theatre; "as background music, mood music, music between acts or scenes, or as sound effects for enrichment or distraction" (9). The essence of human voice as primary pivot or source of sound, "words as movements", pauses, modulation, pitch, silence, as well as other sounds and sound effect like music, rain, thunder, doorbell, wind, clap, telephone bells, automobiles and airplane noises, are well known as ingredients towards meaningful theatre production. Over the years, sound and music have served variously as accompaniments in theatre production. Downs, Wright and Ramsey elucidate further on the developmental trajectories of sound and music in theatre production when they averred that:

The ancient Greeks used simple implements to imitate wind, rain, and thunder. The Romans went further and built copper-lined thunder tunnels in the floors of their theatres. Stage hands dropped boulders down these tunnels to create the sound of distant thunder.... Today's sound designers can record, mix, filter, reverberate, modulate, amplify, and cue up sound effects exactly when they are needed. They record sounds from real life, and they use sounds from vast sound library that contain everything. (213)

Theatre production rests squarely on the viability of sound and visual components for its meaning and the audience's satisfaction. The audience who are boxed up in the dark auditorium can only enjoy the performance when these complementary partnerships are judiciously deployed in the performance to deepen the audience-actor relationship and enhance understanding of the total concept of the production. Sound according to Enendu "is a positive component of theatre production which, by its nature and signification, contrasts with silence and noise. Sound creates, primarily, dramatic meaning, moments and atmosphere.... Sound and vision are fundamental to perception and form the underlying basis in theatre communication" (19). Both of these components make up the theatrical elements of production. They are as vital and as old as theatre; and are traditionally inseparable.

\section{Space, Movement, Rhythm and Picturization}

Every space, be it architecturally designed or ad-hoc can make a good theatre performance space provided it meets with the demand 
of pre-production, run of production and post-production processes. A suitable work-space and environment supported by necessary tools and equipment for the artistes and technicians is a sine qua non to theatrical production. Although different production demands and styles need different settings, no space is claimed fully adequate except when delineated to suit a particular production or production space. However, certain architectural and or ad-hoc spaces suit certain productions. Yet, the best description for a theatre is a formal, purpose built theatre house or an informal venue. In any case, the 'ideal' form of theatre is one whose architectural structure, orientation and configuration can accommodate both the actors and the audience and production demands. Two spaces within the theatre architecture are indispensable for the theatre practice. These are the auditorium - the part of the theatre in which the audience sit to watch a live performance and the stage - the part of the theatre wholly reserved for the performers. The planning, designing, conception and orientation of these spaces affect the production in question. This is evident in its visual symbolism and interpretation. Of note however, is the attention this paper has given to the proscenium stage architecture because of the inherent unidirectional oriented configuration through which a lot of realism can be achieved through the projection of lights, scenery and costume, the major visual components of any theatre production. On the hand, achieving rhythm in a theatre production is a foremost duty of the discerning director. Rhythm is enhanced through movement and speech (lines and movement). No matter the stage architecture, the director owes it a duty to the audience to piece up the rhythm of the performance through the different cues of the actors. Another significant component of rhythm is the actor's acting area, positioning and general picturization on stage. The stage is divided into different acting areas with their different strengths and weaknesses. Depending on the position of the actor, balancing of the actors is a major factor to ensuring and achieving good picturization. From the footlights near the orchestra, the down stage, centre stage and upstage, each of these acting areas presents its own challenges to the director in terms of achieving a pictorial overview and philosophy of the production. Robert Edward Jones quoted in George Kernodle describes the significance of space thus:

A setting is not just a beautiful thing, a collection of beautiful things. It is a presence, a mood, a warm wind fanning the drama to flame. It echoes, it enhances, it animates. It is an expectancy, a foreboding, a tension. It says nothing, but it gives everything.... The 


\begin{abstract}
designer creates an environment in which all noble emotions are possible. Then he retires. The actor enters. If the designer's work has been good, it disappears from our consciousness at the moment.... The actor has taken the stage; and the designer's only reward lies in the praise bestowed on the actor. (412)
\end{abstract}

From the foregoing, the paper has chronicled the many components of visual symbolism in any theatre production to include; light, set, costume, makeup, sound, music, movement, rhythm and picturization as well as the different staging peculiarities. It behooves the director who is worth his onion and his design team to deploy a revolutionary approach to the application of the visual aesthetics that will keep the audience glued to the seat throughout the duration of the run of production. Especially with our insatiable audience of the present times, all efforts must be channeled to creating a spectacular theatre production where visual satisfaction is paramount without undermining the many arts that make up a theatre production.

Visual Symbols and the Challenges to Modern Audience Reality With audiences that are partially knowledgeable to the theatrical practice, wooing and keeping them in the theatre for as much as two hours become a herculean task. It is even more daunting a task when such an audience meets a drab performance owing to lack of a quantum deployment of visual aesthetics or an outright lack of cohesion in the play production. Considering the 21stcentury age where technology has virtually taken over the traditional means of entertainment including theatre going, the only means available for the theatre and its practitioner is the visual symbol and how best to apply it and win back the theatre patrons. Edwin Wilson captures the scenario in these words: When audiences attend a theatre event, they bring more than their mere presence; they bring a background of personal knowledge and a set of expectations that shape the experience.... Including the link between theatre and society, their awareness of the social, political, and philosophical world in which the play was written or produced, their specific information about the play and playwright (44).

Against this background, it is the duty of the director and technical team to design, develop and deliver an aesthetically spectacular performance that will not only appeal to the visual and auditory senses but also to the intellect. Ola Rotimi quoted in Barclays Ayakoroma reveals the temperament of an average African audience thus: "If 
you're good, the African audience lets you know in the instant of your acting, by its reaction. If you're bad, it lets you know as well. You don't have to wait, as in Europe or America, till the following day or days later for a critic arrogating to himself the perception of the majority, to tell you how you fared, in a column or two of a newspaper". (104)

The reality of the modern audience and theatre patronage is that sandwiched between the internet age and the accessibility of entertainment on the go, made possible through the social media. Talking about the internet and the social media, a visit to the home page on Facebook, WhatsApp Forum, We-Chat, BBM, Instagram, etc., would convince any discerning critic that the social media have become an entertainment hub where individuals visit and relieve themselves of the boredom of life. Whatever your perception of life, you will find an aspect that meets your entertainment needs; from the comic, the tragic, the melodramatic, to extreme sarcasm. You will cry, laugh, and in some instances be left despondent to the many societal upheavals on display.

The truism of the social media being at the verge of supplanting the traditional entertainment outfits including theatre is not in contention. But how can theatre retrace its steps to the good old days when theatre patrons converged in one venue and shared that group experience using the immediacy of the actor-audience relationship that sets theatre far apart from any other form of entertainment? Having established the nature of an African audience to theatre production, the challenge of the social media and a possible apathy to live theatre, the only opening and leeway left is to reawaken the consciousness of a theatre going spirit in the audience through the deployment of visual symbols which are though, an age long components of theatre production but which can be revolutionized in their application to attract the audience to once again, be part of the overall theatre process.

The visual symbols that enhance aesthetic appeal in theatre production and as already discussed include; light, scenery, costume, makeup, sound and music. Other components are picturization, movement, rhythm and stage geography and its peculiarities. By deploying these components properly in their variant dimensions and within the conceptual and philosophical demands of the production, the audience's interest would be aroused and sustained. For example, in set design, the Computer Aided Design (CAD) has become common in modern stage designs. Therefore, if this method is deployed in Nigerian theatre production, every performance will be a box office success. In the same vein, lighting in theatre has been most favoured. According to Downs, Wright and Ramsey, "one of the most important 
advances in lighting design was the invention of computerized lighting, which allows an entire lighting design, including hundreds of exact levels and cues, to be controlled by a computerized light board called a dimmer" (210). With such revolution in light, the audience will surely benefit in the smoothness and consistency of the same show every night with just a touch of the button. In sound and music design, it is the same success story for the present day audience who dares to near the theatre. With a digital sound console at the disposal of the sound designer, all sound effects and music accompaniments are stored for easy retrieval and deployment at an instance in the run of production. For according to Orok in Enendu and Okome, "in order to succeed, it is often necessary to combine both sound and visual effects simultaneously. For example, a number of special lighting effects can provide the visual illusion of fire, but the sound of cracking of wood completes the overall effect" (37). Therefore, having each of the beats required for every cue in the digital console places the sound and music designer on a successful path in the run of production and significantly contributes to swaying the audience opinion about theatre patronage. Costume helps in the delineation of characters and deepens the meaning of the play, and in recent times, emphasis placed on realistic costuming has also revolutionized this component of visual symbol for the theatre patron to identify actors' social status, occupation and many more. Using a costume chart and costume parade as guides, the costume designer has become more contemporary and is able to apply his wherewithal to the whole theatre process with much innovation and creativity of purpose.

\section{Conclusion}

The popularity of the visual symbols so far analysed is hinged on their functionality and as complementary components to every aspect of the theatre process. However, these visual symbols are inescapable endeavours and tools that enhance the communicativeness of a theatre production. It involves collaboration of diverse professionals and craftmen with diverse techniques, technologies, crafts, creative spirits and experience to achieve desired result. The director is the man behind the mask of theatre glory for guiding all other units of the production to become a successful whole. These results in their visualization are the catalyst and livewire upon which the audiences rely to wittingly make informed opinion about theatre patronage. Visual symbolism is thus an integral aspect of contemporary theatre practice that when properly deployed will surely awaken the dead spirit of theatre patronage even in the face of the social media challenge. 


\section{Works Cited}

Ayakoroma, Barclays. Theatre Management in Nigeria: An Introduction. Ibadan: Kraft Books Limited, 2014. Print.

Bentham, Frederick. The Art of Stage Lighting. London: Pitman Publishers, 1976. Print.

Dean, Alexander \& Lawrence Carra. Fundamentals of Play Directing. New York: Holt, Rinehart and Winston, 1965. Print.

Downs, William, Lou Wright and Erik Ramsey. The Art of Theatre: Then and Now. $3^{\text {rd }}$ Ed. USA: Wadsworth CENGAGE Learning, 2013. Print.

Effiong, Bassey (Introduction) in Oko Edisua Offoboche (ed.) Six Plays with Notes for the Beginner Director. Calabar: Cross River State Newspaper Corp., 1992. Print.

Enendu, Molinta. "Fundamental Reflections in Stage Design" in CAJOLIS Vol.1 N0.1 Kalu Uka (ed.) Calabar: Centeur Publishers, 1989. Print.

"Sound and Acoustics in Theatre Planning and Installation" in Molinta Enendu \& Onookome Okome (ed.) The Sight of Sound: Sound in the Media and Theatre. Ibadan: Kraft Books, 1994.17-31. Print.

—. "The Effects of Architectural Structures on Technical Directing in Two Nigerian Theatres" University of Calabar: PhD Thesis, 2000. Print.

Grotowski, Jerzy. Towards a Poor Theatre. London: Methuen Publishers, 1981. Print.

Iji, Edde. "The Sight of Sound: Theorizing Sound on Stage and the Media: An Introduction" The Sight of Sound: Sound in the Media and Theatre. Ed. Molinta Enendu and Onookome Okome Kraft Books Ltd, 1994. 9-16 Print.

Kernodle, George. Invitation to the Theatre. New York: Harcourt, Brace \& World Inc., 1967. Print.

MacBride, Sean. Many Voices One World. Ibadan: Ibadan University Press, 1984. Print.

Ododo, Sunday. Technical Aids as an Integral Part of Play Production: Illustrated with Plays of Femi Osofisan an unpublished M.A. Thesis, Ibadan: Department of Theatre Arts, University of Ibadan, 1988. Print.

Orji, Bernard. "Interculturality and Hybridity in Okumkpo Masquerade Performance of Akpoha-Afikpo. University of Ibadan: MA Dissertation. 2012. Print.

Orok, Imaikop. "Music and Sound in Theatrical Production: The Calabar University Theatre Productions." The Sight of Sound: Sound 
in the Media and Theatre. Ed. Molinta Enendu and Onookome Okome. Ibadan: Kraft Books, 1994. 32-44. Print.

Utoh-Ezeajugh, Tracie. "Promoting Minority Cultures through Costume and Makeup: Sam Ukala's Break a Boil in Production." Theatre and Minority Rights: Perspectives on the Niger Delta. Ed. Austin Asagba. Ibadan: Kraft Books, 2010 129-141. Print.

Wilson, Edwin. The Theatre Experience. $5^{\text {th }}$ ed. New York: McGrawHill, Inc. 1991. Print. 